\title{
Upper thoracic spine mobilization and mobility exercise versus upper cervical spine mobilization and stabilization exercise in individuals with forward head posture: a randomized clinical trial
}

\author{
Juchul Cho ${ }^{1}$, Eunsang Lee ${ }^{1}$ and Seungwon Lee ${ }^{2^{*}}$ (D)
}

\begin{abstract}
Background: Although upper cervical and upper thoracic spine mobilization plus therapeutic exercises are common interventions for the management of forward head posture (FHP), no study has directly compared the effectiveness of cervical spine mobilization and stabilization exercise with that of thoracic spine mobilization and mobility exercise in individuals with FHP.

Methods: Thirty-two participants with FHP were randomized into the cervical group or the thoracic group. The treatment period was 4 weeks, with follow-up assessment at 4 and 6 weeks after the initial examination. Outcome measures including the craniovertebral angle (CVA), cervical range of motion, numeric pain rating scale (NPRS), pressure pain threshold, neck disability index (NDI), and global rating of change (GRC) were collected. Data were examined with a two-way repeated-measures analysis of variance (group $\times$ time).

Results: Participants in the thoracic group demonstrated significant improvements $(p<.05)$ in CVA, cervical extension, NPRS, and NDI at the 6-week follow-up compared with those in the cervical group. In addition, 11 of 15 (68.8\%) participants in the thoracic group compared with 8 of 16 participants (50\%) in the cervical group showed a GRC score of +4 or higher at the 4-week follow-up.

Conclusions: The combination of upper thoracic spine mobilization and mobility exercise demonstrated better overall short-term outcomes in CVA (standing position), cervical extension, NPRS, NDI, and GRC compared with upper cervical spine mobilization and stabilization exercise in individuals with FHP.
\end{abstract}

Trial registration: KCT0002307, April 11, 2017 (retrospectively registered).

Keywords: Mobilization, Therapeutic exercises, Forward head posture, Neck pain

\section{Background}

Many people living in modern society experience neck pain. Moreover, the increasing use of smartphones has resulted in increasing incidence of neck pain [1-3]. During smartphone use, the user's neck is more bent than when looking at video display terminals in general [4], and neck pain can occur because the cervical extensor

\footnotetext{
* Correspondence: swlee@syu.ac.kr

2Department of Physical Therapy, Sahmyook University, 815, Hwarang-ro,

Nowon-gu, Seoul, South Korea

Full list of author information is available at the end of the article
}

becomes activated and the load on the erector spinae increases in order to adjust the neck balance [4]. Additionally, touching the screen and using the smartphone for a long time without supporting the arm causes fatigue of the neck and shoulder, and increases the load on the cervical spine [5]. Continuous load on the cervical spine leads to variations in the spinal curve, resulting in degenerative change of joints, a straight cervical spine, and forward head posture (FHP) [6-8], which can worsen and progress to cervical herniation of the intervertebral disc [9]. FHP is defined as increased extension 
of the upper cervical spine and increased flexion of the lower cervical spine and upper thoracic spine, with the head position around the sagittal plane showing forward deviation from the gravity line $[10,11]$. In the FHP position, the loads applied to the muscles around the neck and shoulder are 3.6 times the loads in the normal position [12]. Particularly, FHP causes shortening of the sternocleidomastoid, scalenus anterior, and upper trapezius muscles, and lengthening of the levator scapulae and semispinalis capitis muscles, leading to abnormal activation of the cervical spine flexor and extensor muscles [13].

Previous studies reported that $60 \%$ of patients with neck and shoulder pain presented with FHP [14], and FHP caused asymmetric muscle activation in the spine (which is an important indicator of neck pain), restricted functional activity, and caused spine deviation and lateral inclination of the pelvis [15-17]. Cervical instability results from hypomobility of the upper cervical spine and upper thoracic spine and hypermobility of the lower cervical spine. Particularly, the protective action of movement and the reaction force is decreased by the induced change in vertebral structures [18]. Therefore, most clinicians examine the thoracic spine in individuals with neck pain $[19,20]$. Dysfunction of the lower cervical spine and articular disc lesions can be causes of pain in the upper thoracic spine, and dysfunction of the upper thoracic spine restricts the movement of the cervical spine and causes pain [21, 22]. These biomechanical relations of the cervical spine and the thoracic spine are related to movement and become important factors causing neck pain [23]. Some studies report that neck pain and range of motion were improved by applying manual therapy on the upper thoracic spine and on the cervical spine of patients with neck pain, thus improving their movement $[24,25]$.

In clinical practice, physical therapists generally use different modalities, therapeutic exercises, non-thrust mobilization, and thrust manipulation as representative interventions to improve neck pain and FHP [26-29]. A review of the literature highlights recent studies that investigated interventions with manual therapy and active exercise in acute and chronic cervical diseases $[30,31]$. Particularly, it was proposed that a combination of manual therapy and therapeutic exercise is effective for the management of mechanical neck pain [28]. There are two types of manual therapy: joint mobilization and joint manipulation [20,32]. However, previous studies suggested that adverse effects, such as local discomfort, headache, dizziness, and malaise were fewer in mobilization than in manipulation [33, 34]. A study on joint mobilization and manipulation therapy reported that the two types of therapies showed equivalent efficacy [35].
Although many studies have been conducted on patients with neck pain, there is insufficient evidence on the effectiveness of the combination of joint mobilization and therapeutic exercise in individuals with FHP. Therefore, the purpose of this study was to identify the effect of the combination of joint mobilization and therapeutic exercises in improving pain and movement in individuals with FHP. In addition, although most previous studies focused on the cervical spine, this study aimed to identify the effect of intervention on the upper thoracic spine.

\section{Methods \\ Participants}

In this study, 32 participants with neck pain from FHP were recruited in the Department of Rehabilitation Medicine of K University Hospital from November to December 2016. The following inclusion criteria were applied: participants should have a primary complaint of neck pain (pain between the posterior part of the cervical spine and the interscapular region), age from 20 to 29 years (age at which there is no degenerative change and deformation of the cervical vertebrae), and symptoms of FHP. For the diagnosis of FHP, the craniovertebral angle (CVA) was evaluated. Participants were excluded if they presented any serious pathology such as tumor, had history of whiplash injury within 3 months of the examination, underwent prior surgery to the cervical or thoracic spine, and exhibited positive neurologic signs consistent with nerve root compression. The protocol for the study was approved by the Institutional Review Board of Sahmyook University. All participants provided informed consent before their participation in the study.

\section{Examination procedures}

All participants underwent demographic information collection and physical examination. The cervical spine and thoracic spine were evaluated in the sitting and prone positions, and a passive physiological intervertebral motion test (which used physiological movements such as flexion, extension, lateral-flexion, and rotation) and a passive accessory intervertebral motion test were conducted [20,36]. Spurling's test, compression test, distraction test, and upper limb tension tests were performed as special tests for neurological signs and symptoms [32]. The study period lasted for 6 weeks. Evaluations were conducted before and after treatment. Each intervention was applied 10 times for 4 weeks, and follow-up evaluation was conducted after 2 weeks. The cervical group performed upper cervical mobilization and cervical retraction exercise. The thoracic group performed upper thoracic mobilization and upper thoracic extension exercise. The interventions were administered by one physical therapist who had a clinical experience of 13 years and has completed $>300 \mathrm{~h}$ of the manual therapy education course. 


\section{Randomization}

One of three physical therapists recruited participants who met the eligibility criteria, and collected all data on baseline characteristics of participants. After the baseline examination, the 32 participants were randomly assigned to either the cervical group $(n=16)$ or the thoracic group $(\mathrm{n}=16)$ by selecting one of two cards from a box (Fig. 1). The participants were not informed of the research hypothesis, and the evaluator was blinded to the participants' assignment to the treatment groups. All participants were instructed not to discuss any information related to the studied treatments with the other participants.

\section{Cervical group}

The participant sat in the correct posture on a chair with back rest, and the therapist stood facing the left trunk of the participant to apply the mobilization improving the flexion of the upper cervical spine (C1-2) [32]. The therapist covered the rear of the cervical part of the participant with his right hand for stabilization, and placed his thumb and index fingers on the atlas of the participant. To conduct the atlanto-occipital mobilization, the therapist placed his left hand at the right side of the participant and at the same time placed his fifth finger under the occipital area and pulled the participant's head toward his trunk. C1-2 segmental mobilization was conducted to improve flexion according to the convex rule by moving the occipital condyle of the participant to the backward direction by using the trunk and left hand of the therapist. That is, the therapist made the patient increase the inward motion of the chin. After joint mobilization was conducted on one occipital condyle, the same procedure was applied to the other side. The discomfort of the participant was checked during the joint mobilization, which was conducted for $30 \mathrm{~s}$, three times for each segment. The mobilization lasted for a total of $<5 \mathrm{~min}$, with a $10 \mathrm{~s}$ break between the mobilizations of each joint. The total time of intersegmental movement and break intervals was $30 \mathrm{~s}$.

The cervical retraction exercise that was used in a previous study was modified and performed as the cervical spine stabilization exercise in this study [37]. The participants performed cervical retraction by breathing in until gaining the feeling that the occipital bone was pushed back, while sitting straight on a chair with back rest. During the performance of the exercise, the therapist re-educated the participant through the palpation and observation of cervical segments in order not to generate compensation. A total of three sets were conducted, with one set consisting of repeating the motion that was maintained for $10 \mathrm{~s}$ up to 10 times. A break of $5 \mathrm{~s}$ was provided per one movement and $30 \mathrm{~s}$ per one set. Therefore, the total exercise time was $<10 \mathrm{~min}$ (Fig. 2).

\section{Thoracic group}

The participants were placed in the prone position and the therapist stood facing the joint where the mobilization will be applied to improve the extension of the upper thoracic spine (T1-2) [32]. The index and middle fingers of the left hand of the therapist were placed on the vertebral transverse process of the

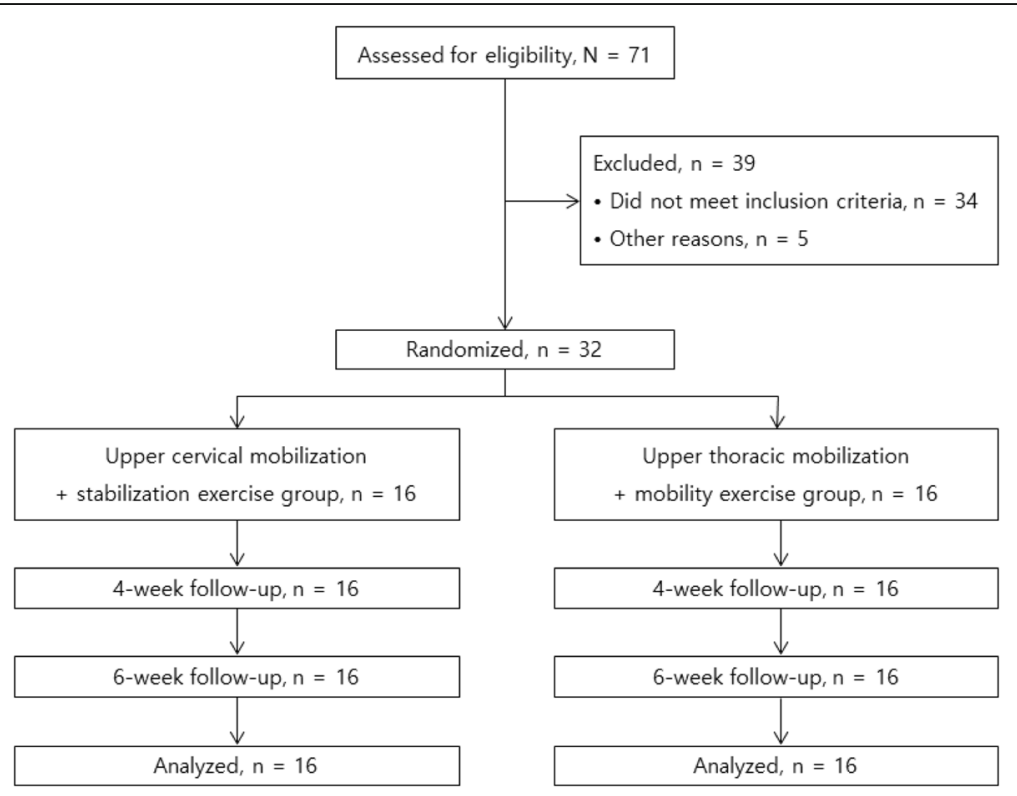

Fig. 1 Flowchart of the recruitment, randomization, and follow-up of participants 


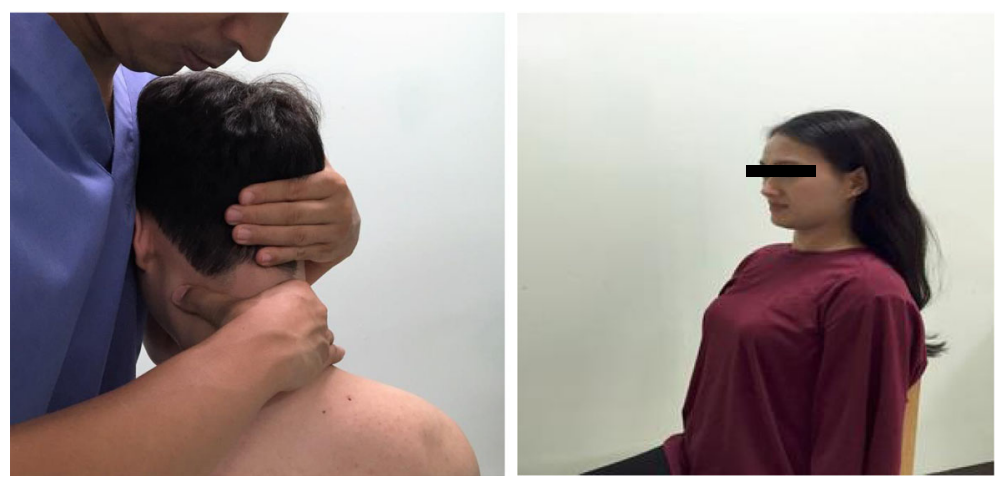

Fig. 2 Upper cervical (C1-2) spine mobilization and stabilization exercise used in this study

participant, which was located in the caudal side of the targeted segment. After the observation of the movement by palpating the area between the spinous processes of selected segments by using the index finger of the right hand of the therapist, the lateral side of the right palm of the therapist was placed on the index and middle fingers of his left hand, and thoracic segmental mobilization was conducted from ventral to caudal direction. Additional wedge was also used to generate exact and strong local movement in the targeted segment. The intervention time was the same as in the cervical group.

Upper thoracic extension exercise was conducted by correcting and supplementing the prone trunk lift that was used in a previous study in order to improve the thoracic mobility [38]. The participant covered his or her cervical spine with both hands and lifted his or her upper body slowly, until gaining the feeling that the occipital bone was pushed upward after moving the chin inward. During the performance of the movement, the therapist re-educated the participant through the palpation and observation of upper thoracic segments. The intervention time was the same as in the cervical group (Fig. 3).

\section{Outcome measures}

Primary outcome measure consisted of the CVA, which was measured using the photograph of the profile of each participant. The participants were made to maintain the natural head posture through the measurement method of self-balance posture [39]. The CVA was the angle made by the line that connects the seventh cervical spine with the tragus and the horizontal line of the seventh cervical spine in the sitting and standing positions, and a CVA of $<49^{\circ}$ was categorized as FHP in previous studies [40, 41]. In a previous study, CVA measurement was reported to have a high reliability [42].

The secondary outcome measures included the cervical range of motion (CROM), numeric pain rating scale (NPRS), pressure pain threshold (PPT), neck disability index (NDI), and global rating of change (GRC). A CROM device (Deluxe inclinometer; Performance Attainment Associates and Mednet Technologies Inc., Roseville, MN, USA) was used to test the active range of motion of the cervical spine. The highest intra-tester reliability (intra-class correlation coefficient [ICC] = 0.87-0.96) for patients with neck pain was identified [43], and the minimal detectable change (MDC) of the CROM had a variation of $5^{\circ}$ to $10^{\circ}[44,45]$. To measure
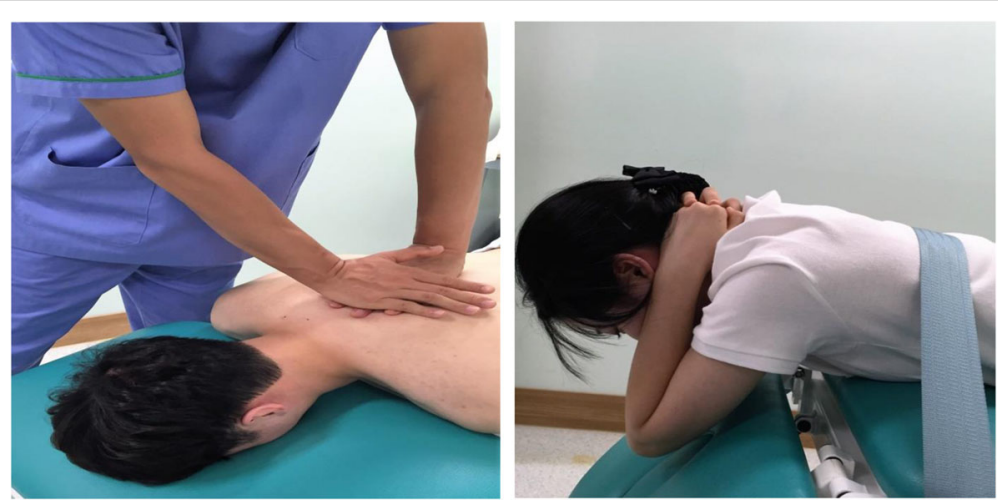

Fig. 3 Upper thoracic (T1-2) spine mobilization and mobility exercise used in this study 
intensity of their current pain, we used an 11-point NPRS, and the NPRS has been shown to have high reliability and validity in previous studies. [46, 47]. An MDC of 2.1 points, with a minimal clinically important difference (MCID) of 1.3 points, was indicated for patients with neck pain [48]. A pressure algometer (J-Tech 121485 Commander Algometer; JTECH Medical, Midvale, UT, USA) was used to identify the change of the PPT after the therapeutic intervention. PPT was measured by targeting the upper fibers of the trapezius when the participants were in the sitting position. In pressure algometry, the intra-rater reliability (ICC $=0.94-0.97$ ) and inter-rater reliability (ICC $=0.79-0.90)$ were identified for patients with neck pain, and it was indicated that the MDC was $47.2 \mathrm{kPa}$ [49]. The NDI was used to evaluate the disability index of the cervical spine [50]. The NDI has been demonstrated to be a valid evaluative tool for patients with neck pain. In a recent systematic review of the literature, it was concluded that the NDI has an MDC of $10 \%$, with an MCID of $14 \%$ [51]. The GRC was used to assess the patient satisfaction after the intervention only. [52]. GRC is used as an objective means to test the improvement of patient symptoms, to identify the intervention effect after treatment completion in clinical practice, and this scale has been shown to have reliability and validity in previous studies. The MCID has been reported as a 3-point change from the baseline value [53]. All outcome measures were collected by an assessor blinded to the group assignments.

\section{Sample size}

The number of required participants was calculated using G*Power 3.1 [54]. This study was set according to effect size $f(V) 0.84$ of the NPRS in a previous study [55] that compared the effect of manipulation of the cervical and the thoracic spine of patients with neck pain. The sample size was statistically calculated using analysis of variance (ANOVA), with the following features: repeated measures, within-between interaction, power $(1-\beta$ err prob) 0.80 , and alpha level .05 . Allowing for a conservative dropout rate of $20 \%$, we planned to recruit at least 32 participants in this study.

\section{Data analysis}

The baseline characteristics of participants were compared between treatment groups, using independent $t$ tests and chi-square tests to assess the adequacy of the randomization (Table 1). The effects of interventions on posture, mobility, and pain was examined by use of a two-way repeated-measures ANOVA, with the treatment group (cervical spine vs. thoracic spine) as the betweenparticipant variable and time (baseline, 4 weeks followup, and 6 weeks follow-up) as the within-participant variable. In addition, GRC score for the between groups were compared using an independent $t$ test. Data analysis was conducted using SPSS (version 18.0; SPSS Inc., Chicago, IL, USA) statistical software. Statistical significance was set at $p<.05$.

\section{Results}

The baseline characteristics were similar between the groups for all variables $(p>.42)$ (Table 1$)$. The withingroup change scores and between-group differences along with 95\% confidence intervals (CI) for all outcome measures can be found in Tables 2 and 3. The participants reported no adverse events during the treatment period, nor were any identified during the 6-week follow-up.

In this study, the active cervical extension showed a significant group-by-time interaction $\left(\mathrm{F}_{2,29}=3.882, p=.026\right.$, $\left.\eta_{\mathrm{p}}^{2}=.115\right)$, with the thoracic group indicating significantly $\left(\mathrm{t}_{29}=2.54, p=.016\right)$ better improvement in active cervical extension $\left(7.5^{\circ}\right.$; $95 \%$ CI: $\left.3.7,11.3\right)$ over time than those in the cervical group $\left(1.3^{\circ} ; 95 \% \mathrm{CI}:-4.0,6.6\right)$. However, no significant group-by-time interaction was observed for CROM, as measured using flexion, lateral flexion, and rotation. The CVA (standing position) showed a significant group-by-time interaction $\left(\mathrm{F}_{2,29}=4.549, \quad p=.014, \quad \eta_{\mathrm{p}}^{2}\right.$ $=.132$ ), with the thoracic group indicating significantly $\left(\mathrm{t}_{29}=2.13, p=.042\right)$ better improvement in CVA (3.9 ${ }^{\circ}$; $95 \%$ CI: 1.8, 6.0) over time than those in the cervical group $\left(0.6^{\circ}\right.$; $95 \%$ CI: $\left.-1.9,3.1\right)$. However, the CVA (sitting position) demonstrated no significant group-by-time interaction. The NPRS showed a significant group-by-time interaction $\left(\mathrm{F}_{2,29}=9.779, p=.001, \eta_{\mathrm{p}}^{2}=.246\right)$, with the thoracic group indicating better pain reduction over time

Table 1 Baseline demographics for the two groups

\begin{tabular}{llll}
\hline Baseline variable & Cervical group $(n=16)^{\mathrm{a}}$ & Thoracic group $(n=16)^{\mathrm{a}}$ & $p$-Value \\
\hline Age (years) & $23.8(2.6)$ & $23.9(3.1)$ & $.951^{\dagger}$ \\
Sex (female), number (\%) & $12(75.0)$ & $11(68.8)$ & $.694^{\ddagger}$ \\
Height (cm) & $164.0(6.3)$ & $165.8(7.9)$ & $.495^{\dagger}$ \\
Weight (kg) & $57.0(11.3)$ & $56.3(10.6)$ & $.861^{\dagger}$ \\
Duration of symptoms (months) & $32.9(26.0)$ & $24.8(30.0)$ & $.420^{\dagger}$ \\
\hline
\end{tabular}

${ }^{a}$ Values are mean (standard deviation)

${ }^{\dagger}$ Independent $\mathrm{t}$ test

${ }^{\ddagger}$ Chi-square 
Table 2 Within-group change score and pairwise comparisons of between-group change scores for cervical range of motion

\begin{tabular}{|c|c|c|c|c|c|c|c|}
\hline \multirow[t]{2}{*}{ Measure/group } & \multirow[t]{2}{*}{ Baseline $^{a}$} & \multirow[t]{2}{*}{4 Weeks $^{a}$} & \multirow[t]{2}{*}{6 Weeks $^{a}$} & \multicolumn{2}{|c|}{ Mean within-group differences } & \multicolumn{2}{|c|}{ Mean between-group differences } \\
\hline & & & & Baseline to 4 weeks $^{b}$ & Baseline to 6 weeks $^{b}$ & Baseline to 4 weeks $^{b}$ & Baseline to 6 weeks $^{b}$ \\
\hline \multicolumn{8}{|l|}{ Flexion $\left(^{\circ}\right)$} \\
\hline Cervical group & $49.3(10.1)$ & $57.1(9.3)$ & $53.2(11.5)$ & $7.8(2.8,12.8)$ & $3.9(-0.8,8.7)$ & $2.2(-3.4,7.7) ; p=.428$ & $4.7(-1.0,10.4) ; p=.104$ \\
\hline Thoracic group & $50.6(9.5)$ & $60.6(9.0)$ & $59.3(7.4)$ & $10.0(7.1,13.0)$ & $8.6(5.0,12.2)$ & & \\
\hline \multicolumn{8}{|l|}{ Extension $\left(^{\circ}\right)$} \\
\hline Cervical group & $63.3(8.4)$ & $69.6(8.1)$ & $64.6(7.3)$ & $6.3(2.4,10.2)$ & $1.3(-4.0,6.6)$ & $3.9(-0.9,8.8) ; p=.108$ & $6.2(1.2,11.2) ; p=.016$ \\
\hline Thoracic group & $59.7(9.5)$ & $70.0(9.0)$ & $67.2(8.0)$ & $10.3(5.2,15.3)$ & $7.5(3.7,11.3)$ & & \\
\hline \multicolumn{8}{|c|}{ Right lateral flexion $\left(^{\circ}\right)$} \\
\hline Cervical group & $39.8(5.7)$ & $45.3(5.3)$ & $42.9(4.9)$ & $5.6(3.0,8.2)$ & $3.2(0.0,6.3)$ & $1.2(-2.5,4.9) ; p=.515$ & $-0.4(-4.6,3.8) ; p=.833$ \\
\hline Thoracic group & $37.6(6.1)$ & $44.4(2.9)$ & $40.4(4.4)$ & $6.8(4.0,9.6)$ & $2.8(-0.3,5.8)$ & & \\
\hline \multicolumn{8}{|l|}{ Left lateral flexion $\left(^{\circ}\right)$} \\
\hline Cervical group & $41.9(6.0)$ & $45.8(5.6)$ & $42.4(4.9)$ & $3.9(2.0,5.9)$ & $0.5(-2.2,3.2)$ & $3.4(0.3,6.5) ; p=.033$ & $3.5(-0.1,7.0) ; p=.051$ \\
\hline Thoracic group & $37.2(7.5)$ & $44.5(4.9)$ & $41.2(5.0)$ & $7.3(4.7,9.9)$ & $4.0(1.6,6.5)$ & & \\
\hline \multicolumn{8}{|l|}{ Right rotation $\left(^{\circ}\right)$} \\
\hline Cervical group & $67.4(8.9)$ & $76.3(5.7)$ & $74.3(7.0)$ & $8.9(5.3,12.6)$ & $6.9(3.7,10.0)$ & $4.6(-0.7,1.0) ; p=.088$ & $0.8(-5.2,6.7) ; p=.797$ \\
\hline Thoracic group & $63.7(12.0)$ & $77.3(6.5)$ & $71.3(8.6)$ & $13.6(9.4,17.8)$ & $7.6(2.3,12.9)$ & & \\
\hline \multicolumn{8}{|l|}{ Left rotation $\left(^{\circ}\right)$} \\
\hline Cervical group & $69.1(8.1)$ & $78.3(5.3)$ & $75.2(6.3)$ & $9.1(5.0,13.3)$ & $6.1(1.9,10.2)$ & $5.9(-0.1,12.0) ; p=.054$ & $3.3(-3.9,10.4) ; p=.054$ \\
\hline Thoracic group & $63.6(13.4)$ & $78.6(8.3)$ & $72.9(10.3)$ & $15.1(10.3,19.8)$ & $9.3(3.1,15.4)$ & & \\
\hline
\end{tabular}

Values are mean (standard deviation)

${ }^{b}$ Values are mean ( $95 \%$ confidence interval)

Table 3 Outcome data for craniovertebral angle, neck pain, pain sensitivity, and disability

\begin{tabular}{|c|c|c|c|c|c|c|c|}
\hline \multirow[t]{2}{*}{ Measure/group } & \multirow[t]{2}{*}{ Baseline $^{a}$} & \multirow[t]{2}{*}{4 Weeks $^{a}$} & \multirow[t]{2}{*}{6 Weeks $^{a}$} & \multicolumn{2}{|c|}{ Mean within-group differences } & \multicolumn{2}{|c|}{ Mean between-group differences } \\
\hline & & & & Baseline to 4 weeks $^{\mathrm{b}}$ & Baseline to 6 weeks $^{\mathrm{b}}$ & Baseline to 4 weeks $^{b}$ & Baseline to 6 weeks $^{b}$ \\
\hline \multicolumn{8}{|l|}{ CVA (sitting) } \\
\hline Cervical group & $45.1(3.9)$ & $50.6(4.4)$ & $48.4(5.7)$ & $5.4(2.9,7.9)$ & $3.3(0.1,6.4)$ & $0.9(-2.1,4.0) ; p=.536$ & $2.1(-1.6,6.0) ; p=.252$ \\
\hline Thoracic group & $43.6(3.8)$ & $50.0(3.8)$ & $49.1(3.0)$ & $6.4(4.4,8.4)$ & $5.4(3.0,8.0)$ & & \\
\hline \multicolumn{8}{|l|}{ CVA (standing) } \\
\hline Cervical group & $50.6(4.8)$ & $52.0(5.7)$ & $51.3(5.2)$ & $1.4(-1.2,3.9)$ & $0.6(-1.9,3.1)$ & $4.3(1.2,7.4) ; p=.008$ & $3.3(0.1,6.4) ; p=.042$ \\
\hline Thoracic group & $48.4(4.6)$ & $54.1(4.3)$ & $52.3(3.3)$ & $5.7(3.7,7.7)$ & $3.9(1.8,6.0)$ & & \\
\hline \multicolumn{8}{|l|}{ NPRS (0-10) } \\
\hline Cervical group & $3.6(1.4)$ & $2.3(1.0)$ & $2.3(1.0)$ & $1.3(0.8,1.8)$ & $1.3(0.7,1.9)$ & $1.3(0.6,2.1) ; p<.001$ & $1.4(0.6,2.3) ; p=.002$ \\
\hline Thoracic group & $4.2(1.5)$ & $1.6(0.8)$ & $1.4(0.7)$ & $2.6(2.0,3.2)$ & $2.8(2.0,3.4)$ & & \\
\hline \multicolumn{8}{|l|}{ PPT (kPa) } \\
\hline Cervical group & $35.9(8.2)$ & $48.4(10.5)$ & $46.8(10.0)$ & $12.5(9.7,15.3)$ & $10.8(8.2,13.4)$ & $1.9(-1.4,5.2) ; p=.251$ & $-2.6(-7.0,1.9) ; p=.251$ \\
\hline Thoracic group & $36.3(12.7)$ & $50.6(12.1)$ & $44.5(11.2)$ & $14.4(12.5,16.3)$ & $8.3(4.4,12.1)$ & & \\
\hline \multicolumn{8}{|l|}{ NDI (0-50) } \\
\hline Cervical group & $7.9(4.3)$ & $5.4(3.7)$ & $5.3(3.9)$ & $2.4(1.3,3.6)$ & $2.6(1.6,3.7)$ & $3.3(1.0,5.6) ; p=.006$ & $3.4(1.0,5.8) ; p=.008$ \\
\hline Thoracic group & $10.4(5.0)$ & $4.6(2.2)$ & $4.3(2.0)$ & $5.8(3.7,7.8)$ & $6.1(3.8,8.3)$ & & \\
\hline
\end{tabular}


than those in the cervical group. However, no significant group-by-time interaction was observed for PPT, as measured using a pressure algometer. The NDI showed a significant group-by-time interaction $\left(\mathrm{F}_{2,29}=7.938, p=.004\right.$, $\eta_{\mathrm{p}}^{2}=.209$ ), with the thoracic group indicating better improvement in disability index over time than those in the cervical group. In case of GRC after 4 weeks, the thoracic group demonstrated significantly $\left(\mathrm{t}_{29}=2.725, p=.011\right)$ better improvements on the GRC measure (mean \pm standard deviation, $+4.25 \pm 1.06)$ than the cervical group $(+3.37 \pm$ 0.72 ), with a mean difference between groups of 0.87 points (95\% CI: 0.2, 1.5).

\section{Discussion}

The results of this study corresponded with those of a previous research that shows the efficacy of manipulation and mobilization of the cervical and thoracic spine in patients with neck pain [24,56,57]. The novelty of the current study is that the results suggest that the combination of upper thoracic mobilization and mobility exercise may provide short-term benefits to individuals with FHP.

FHP results in deformation of joints due to poor postures for a long time. Mobilization as treatment was conducted to improve the flexion of the upper cervical spine and to enhance the extension of the upper thoracic spine [32]. According to the purpose of the mobilization, this study showed improvement of the CROM in both groups; however, there was a significant difference between the two groups in cervical spine extension. Previous studies also showed the increase of the range of motion by improving joint hypo-mobility and the adhesion between soft tissues when the joint mobilization technique was applied to patients with mechanical neck pain [23, 58]. Particularly, it was reported that there were more improvements of movement limitation in patients with the most serious pain. In the case of therapeutic exercise, in this study, the stabilization exercise was conducted in the lower cervical spine and the mobility exercise was performed in the upper thoracic spine. The stabilization exercise for the cervical spine was a low-intensity isometric exercise, and the mobility exercise for the thoracic spine was a highintensity exercise against gravity. Thus, better results were obtained in the thoracic spine owing to the difference in intensity despite performing both exercises at the same time. Although the CVA measured from profile photographs also indicated improved results in both groups, in the standing position, there was a significant difference between groups through flow of time and there was an interaction. A previous study reported that thoracic spine mobilization with continuous passive stimulus increased joint mobility and helped in improving the somatosensory system [59]. Because of changes in these qualities and in the quantities of proprioception information, it was indicated that the improvement of spine alignment lead to the difference in CVA. However, the reason why there was no interaction in the sitting position was because the curve of the thoracic and lumbar spines consisted of slight flexion in a comfortable sitting position. Depending on the posture, the difference of spine alignment might be affected in the cervical spine.

The difference of the MDC and MCID of NPRS in both groups is noteworthy. In the present study, the average change score exceeded both the MDC and MCID values in the thoracic group. Although the results indicated that there was a significant within-group difference in the thoracic group, no significant within-group difference can be concluded in the cervical group. The difference between the groups in NPRS was 1.4 points, which exceeded the MCID, indicating the clinically significant effect of the thoracic spine mobilization and mobility exercise. It was, however, considered that the $95 \% \mathrm{CI}(0.6,2.3)$ of the difference included lower values than the MCID. Therefore, although the difference in improvement between groups was statistically significant, the clinical importance was uncertain when the interpretation was performed on the basis of the $95 \%$ CI. For the NDI, although the average change score was $12.2 \%$ in the thoracic group only, which exceeded the MDC, the average difference in change scores between the two groups was $7 \%$, which was lower than the MCID of NDI [51]. Therefore, although the difference in improvement between groups for the NDI was again statistically significant, the gap could be of little importance clinically when the interpretation was performed on the basis of MCID. There was no interaction between the two groups in the pain sensitivity test of the upper trapezius muscle. The reason why the upper trapezius muscle was targeted was to identify the effect of position improvement after the treatment, because the tone of the upper trapezius muscle was increased and became tighter due to upper cross syndrome [60]. This study indicated a significant effect in both groups at 4 weeks after the treatment. The muscle tone of the upper trapezius was decreased by the change of posture through joint mobilization, and cervical instability was improved through the therapeutic exercise. However, there was no interaction between the two groups, and the MCID of PPT was not exceeded because the intervention for the cervical and thoracic spine in this study had no direct effect on the sensitivity of the upper trapezius muscle [49]. Although the mechanism of the effect of the manual therapy on neck pain was not clear, the sensitivity of the mechanical receptor might be changed through the application of continuous passive stimulus to soft tissue [38, 61], and the mechanical stress of the pain generator might be reduced by improving the biomechanical relationship of the cervical spine and the thoracic spine [62,63]. In case of GRC, $68.8 \%$ of the participants in the thoracic 
group and $50 \%$ of the participants in the cervical group showed higher than +4 points, and the difference between the groups was significant. The patients' satisfaction was affected by various factors such as individual pain and the belief and there may be inconsistencies in the results among participants owing to their different environments [64]. However, the intervention for the thoracic group was shown to improve FHP better than the intervention for the cervical group based on the GRC in this study, which indicated that all participants were simultaneously improved in terms of the specific therapy technique.

The results of this study suggest that the correct posture of the cervical spine is important when using touchscreen smartphones; however, the correct alignment of the thoracic spine should be prioritized, and clinical interventions including the cervical spine and thoracic spine should be applied. The most important limitation of this study is the short-term follow-up of 6 weeks and the small sample size. Although the sample size was set by using the effect size of a previous study, it is difficult to generalize the study results to all patients with neck pain from FHP. Moreover, it is difficult to generalize the intervention results of this study to male patients with mechanical cervical pain because the sample comprised only 9 men (23 women). However, we considered that the study results can be generalized to the average population because recent studies have proved that women have a higher rate of neck pain than men [65]. Future studies with a long-term follow-up and evaluating the placebo effect, by investigating three groups including a control group, should be conducted.

\section{Conclusion}

This study demonstrated that individuals with FHP who received the combination of upper thoracic spine mobilization and mobility exercise demonstrated better overall short-term outcomes in terms of the CVA (standing position), cervical extension, NPRS, NDI, and GRC than those who received upper cervical spine mobilization and stabilization exercise. Future studies should examine the effectiveness of different types and dosages of manual therapy, and perform long-term follow-up data collection.

\section{Abbreviations}

ANOVA: Analysis of variance; CROM: Cervical range of motion; CVA: Craniovertebral angle; FHP: Forward head posture; GRC: Global rating of change; NDI: Neck disability index; NPRS: Numeric pain rating scale; PPT: Pressure pain threshold

\section{Acknowledgments}

The authors would like to thank DK Seo, WT Kim, SC Lee, and YS Ha for their participation in the data collection process of this study.

\section{Funding}

This study was not supported by any research fund.

\section{Availability of data and materials}

The datasets supporting the conclusions of this article are included within the article. Raw data can be requested from the corresponding author.

\section{Authors' contributions}

$J C$ and EL participated in the recruitment, data collection, and analysis. JC and SL contributed to the study design and conception, and revision of the manuscript. All authors read and approved the final manuscript.

\section{Authors' information}

Juchul Cho: bbangil11@hanmail.net

Juchul Cho was received the M.S. degrees from Konyang University, Daejeon, Korea. He is currently a doctoral student at Sahmyook University. His main areas of research interest are musculoskeletal disorders and balance disorders. Eunsang Lee: Lespt0430@gmail.com

Eunsang Lee was received the M.S. degrees from Sahmyook University, Seoul, Korea. He is currently a doctoral student at Sahmyook University. His main areas of research interest are sport physical therapy and human movement analysis.

Seungwon Lee: swlee@syu.ac.kr

Seungwon Lee was received the Ph.D. degrees from Sahmyook University, Seoul, Korea. Since 2008, he has been with Department of Physical Therapy, Sahmyook University, where he is currently an Associate Professor. His main areas of research interest are therapeutic exercise, geriatric physical therapy, and physical agents.

\section{Ethics approval and consent to participate}

The protocol for the study was approved by the Institutional Review Board of Sahmyook University. Each author certifies that all investigations were conducted in conformity with ethical principles. All participants provided informed consent before their participation in the study and written were obtained from all participants.

\section{Consent for publication}

The authors have received written consent from participants to publish individual patient data (images).

\section{Competing interests}

The authors declare that they have no financial or non-financial competing interests.

\section{Publisher's Note}

Springer Nature remains neutral with regard to jurisdictional claims in published maps and institutional affiliations.

\section{Author details}

'Department of Physical Therapy, Graduate School of Sahmyook University, 815, Hwarang-ro, Nowon-gu, Seoul, South Korea. ${ }^{2}$ Department of Physical Therapy, Sahmyook University, 815, Hwarang-ro, Nowon-gu, Seoul, South Korea.

Received: 5 June 2017 Accepted: 1 December 2017

Published online: 12 December 2017

\section{References}

1. Cote P, Cassidy JD, Carroll L, Kristman V. The annual incidence and course of neck pain in the general population: a population-based cohort study. Pain 2004;112(3):267-273. Epub 2004/11/25

2. Martin BI, Deyo RA, Mirza SK, Turner JA, Comstock BA, Hollingworth W, et al. Expenditures and health status among adults with back and neck problems. JAMA. 2008;299(6):656-64. Epub 2008/02/14

3. Khedr EM, El Shinawy O, Khedr T, Abdel aziz ali Y, Awad EM. Assessment of corticodiaphragmatic pathway and pulmonary function in acute ischemic stroke patients. Eur J Neurol 2000;7(5):509-516. Epub 2000/10/29.

4. Straker L, Burgess-Limerick R, Pollock C, Coleman J, Skoss R, Maslen B. Children's posture and muscle activity at different computer display heights and during paper information technology use. Hum Factors. 2008:50(1):4961. Epub 2008/03/22

5. Shin G, Zhu X. User discomfort, work posture and muscle activity while using a touchscreen in a desktop PC setting. Ergonomics 2011;54(8):733744. Epub 2011/08/19 
6. Harrison DE, Harrison DD, Betz JJ, Janik TJ, Holland B, Colloca CJ, et al. Increasing the cervical lordosis with chiropractic biophysics seated combined extension-compression and transverse load cervical traction with cervical manipulation: nonrandomized clinical control trial. J Manip Physiol Ther 2003;26(3):139-151. Epub 2003/04/22.

7. Howard RS, Rudd AG, Wolfe CD, Williams AJ. Pathophysiological and clinical aspects of breathing after stroke. Postgrad Med J 2001;77(913):700-702. Epub 2001/10/26.

8. Grob D, Frauenfelder $H$, Mannion AF. The association between cervical spine curvature and neck pain. Eur Spine J 2007;16(5):669-678. Epub 2006/ $11 / 23$.

9. Britto RR, Rezende NR, Marinho KC, Torres JL, Parreira VF, Teixeira-Salmela LF. Inspiratory muscular training in chronic stroke survivors: a randomized controlled trial. Arch Phys Med Rehabil 2011;92(2):184-190. Epub 2011/01/29.

10. Fernandez-de-Las-Penas C, Cuadrado ML, Pareja JA. Myofascial trigger points, neck mobility and forward head posture in unilateral migraine. Cephalalgia 2006;26(9):1061-1070. Epub 2006/08/22

11. Salahzadeh Z, Maroufi N, Ahmadi A, Behtash H, Razmjoo A, Gohari M, et al. Assessment of forward head posture in females: observational and photogrammetry methods. J Back Musculoskelet Rehabil 2014;27(2):131-139. Epub 2013/08/22.

12. Sauter SL, Schleifer LM, Knutson SJ. Work posture, workstation design, and musculoskeletal discomfort in a VDT data entry task. Hum Factors 1991; 33(2):151-167. Epub 1991/04/01.

13. Finley MA, Lee RY. Effect of sitting posture on 3-dimensional scapular kinematics measured by skin-mounted electromagnetic tracking sensors. Arch Phys Med Rehabil 2003;84(4):563-568. Epub 2003/04/12.

14. Chiu TT, Ku WY, Lee MH, Sum WK, Wan MP, Wong CY, et al. A study on the prevalence of and risk factors for neck pain among university academic staff in Hong Kong. J Occup Rehabil 2002;12(2):77-91. Epub 2002/05/17.

15. Correa EC, Berzin F. Efficacy of physical therapy on cervical muscle activity and on body posture in school-age mouth breathing children. Int J Pediatr Otorhinolaryngol 2007;71(10):1527-1535. Epub 2007/07/31.

16. Johnston V, Jull G, Souvlis T, Jimmieson NL. Neck movement and muscle activity characteristics in female office workers with neck pain. Spine (Phila Pa 1976) 2008:33(5):555-563. Epub 2008/03/05.

17. Cibulka MT, Strube MJ, Meier D, Selsor M, Wheatley C, Wilson NG, et al. Symmetrical and asymmetrical hip rotation and its relationship to hip rotator muscle strength. Clin Biomech (Bristol, Avon). 2010;25(1):56-62. Epub 2009/10/17

18. Ning $X$, Haddad $O$, Jin S, Mirka GA. Influence of asymmetry on the flexion relaxation response of the low back musculature. Clin Biomech (Bristol, Avon). 2011;26(1):35-9. Epub 2010/10/15.

19. Dunning JR, Cleland JA, Waldrop MA, Arnot CF, Young IA, Turner M, et al. Upper cervical and upper thoracic thrust manipulation versus nonthrust mobilization in patients with mechanical neck pain: a multicenter randomized clinical trial. J Orthop Sports Phys Ther. 2012;42(1):5-18. Epub 2011/10/08

20. Olson KA. Manual physical therapy of the spine. Elsevier Health Sciences. 2015;

21. Vicenzino B, Collins D, Wright A. The initial effects of a cervical spine manipulative physiotherapy treatment on the pain and dysfunction of lateral epicondylalgia. Pain 1996;68(1):69-74. Epub 1996/11/01.

22. Murphy DR. Conservative management of cervical spine syndromes: McGraw-hill professional; 2000.

23. Kanlayanaphotporn $R$, Chiradejnant A, Vachalathiti $R$. The immediate effects of mobilization technique on pain and range of motion in patients presenting with unilateral neck pain: a randomized controlled trial. Arch Phys Med Rehabil 2009;90(2):187-192. Epub 2009/02/25.

24. Masaracchio M, Cleland JA, Hellman M, Hagins M. Short-term combined effects of thoracic spine thrust manipulation and cervical spine nonthrust manipulation in individuals with mechanical neck pain: a randomized clinical trial. J Orthop Sports Phys Ther 2013;43(3):118-127. Epub 2012/12/12.

25. Dunning JR, Butts R, Mourad F, Young I, Fernandez-de-Las Penas C, Hagins $M$, et al. Upper cervical and upper thoracic manipulation versus mobilization and exercise in patients with cervicogenic headache: a multicenter randomized clinical trial. BMC Musculoskelet Disord 2016;17:64. Epub 2016/02/08.

26. Evans R, Bronfort G, Nelson B, Goldsmith CH. Two-year follow-up of a randomized clinical trial of spinal manipulation and two types of exercise for patients with chronic neck pain. Spine (Phila Pa 1976) 2002;27(21):23832389. Epub 2002/11/20.
27. Roddey TS, Olson SL, Grant SE. The effect of pectoralis muscle stretching on the resting position of the scapula in persons with varying degrees of forward head/rounded shoulder posture. J Man Manip Ther. 2002;10(3):124-8.

28. Childs JD, Cleland JA, Elliott JM, Teyhen DS, Wainner RS, Whitman JM, et al. Neck pain: clinical practice guidelines linked to the international classification of functioning, disability, and health from the orthopedic section of the American Physical Therapy Association. J Orthop Sports Phys Ther. 2008;38(9):A1-A34. Epub 2008/09/02.

29. Lynch SS, Thigpen CA, Mihalik JP, Prentice WE, Padua D. The effects of an exercise intervention on forward head and rounded shoulder postures in elite swimmers. Br J Sports Med 2010;44(5):376-381. Epub 2010/04/08.

30. D'Sylva J, Miller J, Gross A, Burnie SJ, Goldsmith CH, Graham N, et al. Manual therapy with or without physical medicine modalities for neck pain: a systematic review. Man Ther 2010;15(5):415-433. Epub 2010/06/12.

31. Miller J, Gross A, D'Sylva J, Burnie SJ, Goldsmith CH, Graham N, et al. Manual therapy and exercise for neck pain: a systematic review. Man Ther 2010. Epub 2010/07/16

32. Kaltenborn FM, Evjenth $\mathrm{O}$, Kaltenborn TB, Vollowitz E. The spine: basic evaluation and mobilization techniques. 3rd ed. Norli: Oslo, Norway; 1993.

33. Senstad O, Leboeuf-Yde C, Borchgrevink C. Frequency and characteristics of side effects of spinal manipulative therapy. Spine (Phila Pa 1976) 1997;22(4): 435-440; discussion 40-1. Epub 1997/02/15.

34. Ernst $E_{1}$ Canter PH. A systematic review of systematic reviews of spinal manipulation. J R Soc Med 2006;99(4):192-196. Epub 2006/04/01.

35. Hurwitz EL, Morgenstern H, Harber P, Kominski GF, Yu F, Adams AH. A randomized trial of chiropractic manipulation and mobilization for patients with neck pain: clinical outcomes from the UCLA neck-pain study. Am J Public Health 2002;92(10):1634-1641. Epub 2002/10/03.

36. Gonnella C, Paris SV, Kutner M. Reliability in evaluating passive intervertebral motion. Phys Ther 1982;62(4):436-444. Epub 1982/04/01.

37. Young IA, Michener LA, Cleland JA, Aguilera AJ, Snyder AR. Manual therapy, exercise, and traction for patients with cervical radiculopathy: a randomized clinical trial. Phys Ther 2009;89(7):632-642. Epub 2009/05/26.

38. Beneck GJ, Story JW, Donald S. Postural cueing to increase lumbar lordosis increases lumbar multifidus activation during trunk stabilization exercises: Electromyographic assessment using intramuscular electrodes. J Orthop Sports Phys Ther. 2016;46(4):293-9. Epub 2016/03/10

39. Watson DH, Trott PH. Cervical headache: an investigation of natural head posture and upper cervical flexor muscle performance. Cephalalgia 1993; 13(4):272-284; discussion 32. Epub 1993/08/01.

40. Fernandez-de-las-Penas C, Alonso-Blanco C, Cuadrado ML, Pareja JA. Forward head posture and neck mobility in chronic tension-type headache: a blinded, controlled study. Cephalalgia 2006;26(3):314-319. Epub 2006/02/14.

41. Nemmers TM, Miller JW, Hartman MD. Variability of the forward head posture in healthy community-dwelling older women. J Geriatr Phys Ther 2009;32(1):10-14. Epub 2009/10/28.

42. Raine S, Twomey LT. Head and shoulder posture variations in 160 asymptomatic women and men. Arch Phys Med Rehabil 1997;78(11):12151223. Epub 1997/11/20.

43. Fletcher JP, Bandy WD. Intrarater reliability of CROM measurement of cervical spine active range of motion in persons with and without neck pain. J Orthop Sports Phys Ther. 2008;38(10):640-645. Epub 2008/10/02.

44. Youdas JW, Carey JR, Garrett TR. Reliability of measurements of cervical spine range of motion-comparison of three methods. Phys Ther 1991;71(2): 98-104; discussion 5-6. Epub 1991/02/01.

45. Tousignant M, Duclos E, Lafleche S, Mayer A, Tousignant-Laflamme Y, Brosseau $L$, et al. Validity study for the cervical range of motion device used for lateral flexion in patients with neck pain. Spine (Phila Pa 1976) 2002; 27(8):812-817. Epub 2002/04/06.

46. Price DD, Bush FM, Long S, Harkins SW. A comparison of pain measurement characteristics of mechanical visual analogue and simple numerical rating scales. Pain 1994;56(2):217-226. Epub 1994/02/01.

47. Ferreira-Valente MA, Pais-Ribeiro JL, Jensen MP. Validity of four pain intensity rating scales. Pain 2011;152(10):2399-2404. Epub 2011/08/23.

48. Cleland JA, Childs JD, Whitman JM. Psychometric properties of the neck disability index and numeric pain rating scale in patients with mechanical neck pain. Arch Phys Med Rehabil 2008;89(1):69-74. Epub 2008/01/01.

49. Walton DM, Macdermid JC, Nielson W, Teasell RW, Chiasson M, Brown L. Reliability, standard error, and minimum detectable change of clinical pressure pain threshold testing in people with and without acute neck pain. J Orthop Sports Phys Ther. 2011;41(9):644-650. Epub 2011/09/03. 
50. Vernon $\mathrm{H}$, Mior $\mathrm{S}$. The neck disability index: a study of reliability and validity. J Manip Physiol Ther 1991;14(7):409-415. Epub 1991/09/01.

51. MacDermid JC, Walton DM, Avery S, Blanchard A, Etruw E, MCAlpine C, et al. Measurement properties of the neck disability index: a systematic review. J Orthop Sports Phys Ther. 2009;39(5):400-417. Epub 2009/06/13.

52. Cleland JA, Glynn P, Whitman JM, Eberhart SL, MacDonald C, Childs JD. Short-term effects of thrust versus nonthrust mobilization/manipulation directed at the thoracic spine in patients with neck pain: a randomized clinical trial. Phys Ther 2007;87(4):431-440. Epub 2007/03/08.

53. Jaeschke R, Singer J, Guyatt GH. Measurement of health status. Ascertaining the minimal clinically important difference. Control Clin Trials 1989;10(4): 407-415. Epub 1989/12/01

54. Faul F, Erdfelder E, Lang AG, Buchner A. G*power 3: a flexible statistical power analysis program for the social, behavioral, and biomedical sciences. Behav Res Methods 2007:39(2):175-191. Epub 2007/08/19.

55. Puentedura EJ, Landers MR, Cleland JA, Mintken PE, Huijbregts $P$, Fernandez-de-Las-Penas $C$. Thoracic spine thrust manipulation versus cervical spine thrust manipulation in patients with acute neck pain: a randomized clinical trial. J Orthop Sports Phys Ther. 2011;41(4):208-220. Epub 2011/02/22.

56. Cleland JA, Childs JD, McRae M, Palmer JA, Stowell T. Immediate effects of thoracic manipulation in patients with neck pain: a randomized clinical trial. Man Ther 2005;10(2):127-135. Epub 2005/06/01.

57. Gonzalez-Iglesias J, Fernandez-de-las-Penas C, Cleland JA, Gutierrez-Vega Mdel R. Thoracic spine manipulation for the management of patients with neck pain: a randomized clinical trial. J Orthop Sports Phys Ther. 2009;39(1): 20-27. Epub 2009/02/13.

58. McNair PJ, Portero P, Chiquet C, Mawston G, Lavaste F. Acute neck pain: cervical spine range of motion and position sense prior to and after joint mobilization. Man Ther 2007;12(4):390-394. Epub 2006/10/31.

59. Gross AR, Hoving JL, Haines TA, Goldsmith CH, Kay T, Aker P, et al. A Cochrane review of manipulation and mobilization for mechanical neck disorders. Spine (Phila Pa 1976) 2004:29(14):1541-1548. Epub 2004/07/13.

60. Grant R. Physical therapy of the cervical and thoracic spine: Churchill Livingstone; 2002.

61. Norlander S, Nordgren B. Clinical symptoms related to musculoskeletal neck-shoulder pain and mobility in the cervico-thoracic spine. Scand J Rehabil Med 1998;30(4):243-251. Epub 1998/11/24.

62. Griegel-Morris P, Larson K, Mueller-Klaus K, Oatis CA. Incidence of common postural abnormalities in the cervical, shoulder, and thoracic regions and their association with pain in two age groups of healthy subjects. Phys Ther 1992;72(6):425-431. Epub 1992/06/01.

63. Fukui $\mathrm{S}$, Ohseto K, Shiotani M. Patterns of pain induced by distending the thoracic zygapophyseal joints. Reg Anesth 1997;22(4):332-336. Epub 1997/07/01.

64. Bombardier C. Outcome assessments in the evaluation of treatment of spinal disorders: summary and general recommendations. Spine (Phila Pa 1976) 2000;25(24):3100-3103. Epub 2000/12/22.

65. Hoy DG, Protani M, De R, Buchbinder R. The epidemiology of neck pain. Best Pract Res Clin Rheumatol 2010;24(6):783-792. Epub 2011/06/15.

\section{Submit your next manuscript to BioMed Central and we will help you at every step:}

- We accept pre-submission inquiries

- Our selector tool helps you to find the most relevant journal

- We provide round the clock customer support

- Convenient online submission

- Thorough peer review

- Inclusion in PubMed and all major indexing services

- Maximum visibility for your research

Submit your manuscript at www.biomedcentral.com/submit

) Biomed Central 